\title{
OCCULT FOLLICULAR THYROID CARCINOMA - AN UNUSUALPRESENTATION OF MULTIPLE LYTIC BONY METASTASIS IN THE SKULL OF A 66-YEAR MALAY MAN
}

\author{
Md. Tahminur Rahman ${ }^{1}$, Venkatesh R. Naik ${ }^{2}$, Prokash Rao ${ }^{3}$ \\ ${ }^{1}$ Department of Pathology, Ibrahim Medical College \\ ${ }^{2}$ Department of Pathology, University Sains Malaysia \\ 16150 Kubang Kerian, Kota Bharu, Kelantan, Malaysia \\ ${ }^{3}$ Department of Neurosurgery, University Sains Malaysia \\ 16150 Kubang Kerian, Kota Bharu, Kelantan, Malaysia
}

\begin{abstract}
Follicular carcinoma of the thyroid usually presents as nodules with rare cases showing metastasis at diagnosis. But occult follicular carcinoma without any thyroid enlargement and presenting as multiple lytic bone lesions is unusual and relatively rare. Here we report a 66-year old Malay man presenting with occipito-parietal swelling for last two years. He had no thyroid enlargement; no thyroid related symptoms and his biochemical thyroid profile was normal. Computerised tomography of skull reported multiple lytic lesions in the occipito-parietal region. FNAC and histopathological examination confirmed the diagnosis of metastatic follicular carcinoma. We present this case because of the rarity of the disease.
\end{abstract}

Ibrahim Med. Coll. J. 2007; 1(2): 25-27

Key Words: Occult follicular carcinoma thyroid, skull metastasis, normal thyroid findings.

\section{Introduction}

Follicular thyroid carcinoma represents less than $10 \%$ of the thyroid malignancies. The tumor is usually well encapsulated and often demonstrate vascular invasion. Metastasis to regional lymph nodes is rare and spread via vascular channel to bones and lungs are common. Literature review showed most of the metastatic follicular carcinoma had obvious thyroid swelling and many cases had previous thyroid surgery. Metastatic lesions in the skull although rare, usually come from carcinoma of lung, breast, prostate. But metastasis from occult follicular thyroid carcinoma to skull is even rarer and we report here this case because of this. Early diagnosis and initiation of treatment should promise a good prognosis for the patient.

\section{Case report}

A 66 year old Malay man presented with an occipitoparietal swelling for 2 years with a sudden rapid enlargement in the last one year. He had no constitutional symptoms before but for last 2 months he complained of dizziness, tinnitus, loss of weight and loss of appetite. On examination, the swelling measured $15 \times 15 \mathrm{~cm}$ in size. There was no thyroid enlargement. Ultrasonogram (USG) of the thyroid and biochemical thyroid profile $\left(\mathrm{T}_{3}, \mathrm{~T}_{4} \& \mathrm{TSH}\right)$ were normal. X-ray skull showed the mass was eroding the occipital bone. Fine needle aspiration cytology (FNAC) performed prior to resection was reported as suggestive of a metastatic lesion from thyroid (fig:1).

The computed tomography (CT) with contrast showed extensive destruction of the occipital and parietal bones with associated extra axial mass. The mass was predominantly cystic in nature with surrounding areas of hypodensity. There were small calcifications seen within the mass and the mass enhanced vividly with IV contrast. Impression was a skull vault metastasis probably from the kidney, thyroid, prostate or the lungs.

\footnotetext{
Address for Correspondence:

Prof. Md. Tahminur Rahman, Department of Pathology, Ibrahim Medical College

122 Kazi Nazrul Islam Avenue, Shahbag, Dhaka-1000
} 


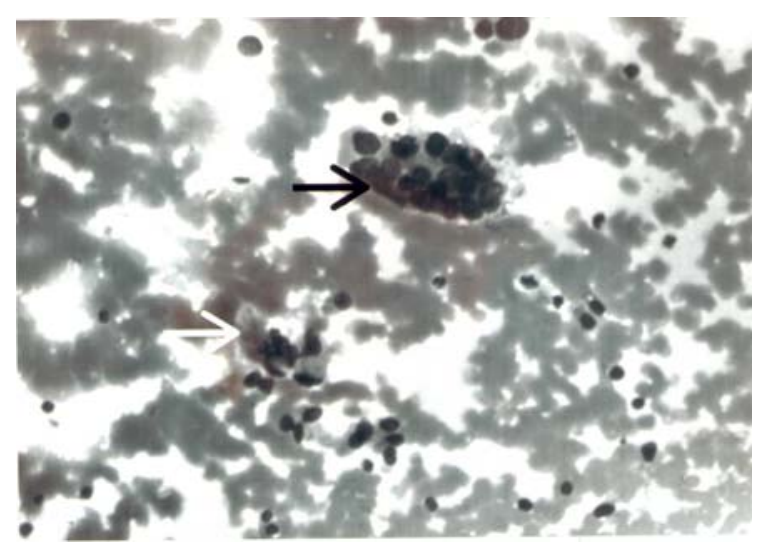

Fig-1: showing the FNAC of the lesion. Clusters of follicular cells (black arrow head) and colloid (white arrow head) are easily recognizable in a bloody background (papanicolaou stain X 40 )

The magnetic imaging resonance (MRI) of brain done with contrast showed a large well defined lesion noted at the vertex measuring $12 \times 10 \times 11.6 \mathrm{cin}$. There was destruction of part of the occipital bone and both parietal bones (Fig 2).

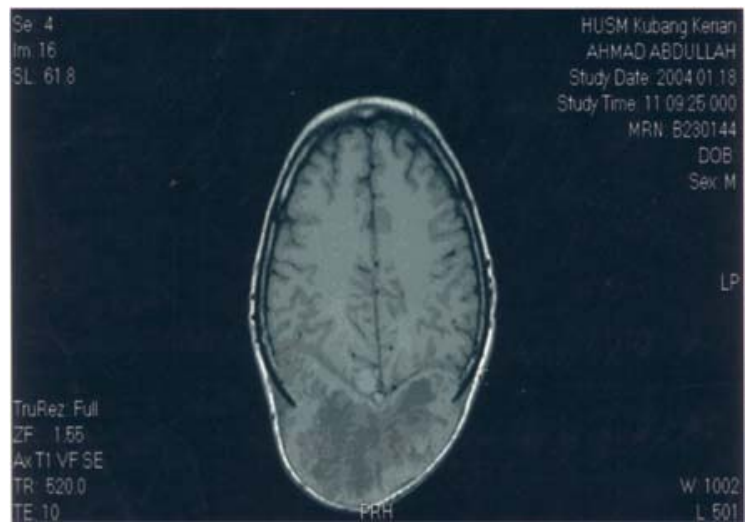

Fig-2: $M R I$ of brain with contrast showing destruction of occipital \& parietal bone \& well defined lesion at vertex.

There were three other small lesions similar to that of the large lesion - one at the parieto-occipital region (just adjacent to the 1arge lesion abutting the brain parenchyma), second one at the right parietal region and the third at the right temporal region. There was no compression on brain, and no midline shift. The basal cisterns and ventricles were not dilated. The MRI features were reported as probable metastasis to the meninges and the skull vault. Ultrasonogram of the whole abdomen and X-ray chest were normal and no metastasis was seen. Routine blood tests showed mild anaemia ( $\mathrm{Hb} 9.1 \mathrm{gm} / \mathrm{d} 1)$. Renal function tests, liver function tests, coagulation profile, serum electrolytes and alpha fetoprotein were normal. The histopathological report from the excised larger fleshy mass removed piece meal under general anesthesia revealed follicles of varying sizes and shapes containing colloid. The follicles were lined by follicular epithelial cells showing mild to moderate nuclear pleomorphism (fig 3). The tumor mass was partly covered by congested fibrocollagenous tissue with evidence of vascular invasion. The immunohistochemistry (IHC) stain with thyroglobulin antibody was strongly positive. Based on these findings it was reported as metastatic follicular carcinoma thyroid.

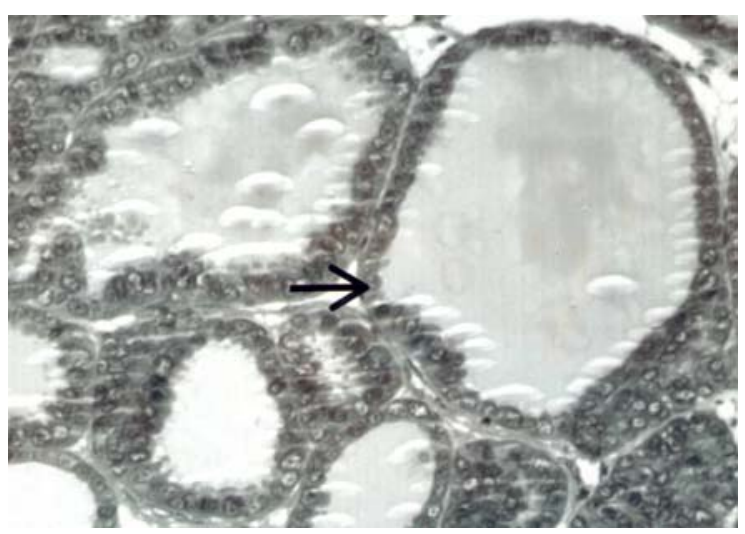

Fig-3: Showing Histopathological features of skull lesion. Follicles of varying sizes and shapes lined by pleomorphic follicular cells containing colloid are easily seen, black arrow head ( $H$ \& E X40)

\section{Discussion}

Follicular thyroid carcinoma usually presents as a thyroid nodule, with rare cases showing metastatic disease at diagnosis. The initial presentation of distant metastases in patients with thyroid carcinoma is an uncommon event ${ }^{1}$. In two large series distant metastases were present at the initial time of diagnosis in about $4 \%$ of cases, $5-11 \%$ in follicular carcinoma thyroid and $2 \%$ in papillary carcinoma thyroid. Metastatic tumors to the skull, though relatively rare most often come from the 1ung, breast, prostate and kidney.

Lytic skull metastasis secondary to thyroid carcinoma has been reported in adolescents ${ }^{2}$ and children ${ }^{3}$. Also follicular carcinoma thyroid presenting as metastasis to kidney ${ }^{4}$, skin $^{5}$, mandible ${ }^{6}$, large pelvic mass ${ }^{7}$, isolated spinal metastasis and solitary skull nodule in children have been reported. 
Metastasis to these unusual sites has often been associated with widespread internal metastatic disease having a poor prognosis. Atypical presentation in the form of a follicular carcinoma associated with hyperthyroidism from a hot nodule in the same lobe and occurrence of both anaplastic and follicular carcinomas are also reported. But occult follicular thyroid carcinoma presenting as multiple skull metastasis in an elderly without any thyroid abnormalities (no thyroid enlargement, biochemical and other thyroid function tests remaining within normal limits) are rare.

The prognosis of follicular carcinoma thyroid is dependent on age, tumor size and vascular invasion. The increasing age, metastasis at the time of first diagnosis and a large tumor size has a bad prognosis. It is important to keep in mind that aggressive investigations and early treatment could increase long term survival by about $40 \%$.

\section{Conclusion}

We report here this case to caution the clinicians to bear in mind about occult follicular carcinoma of thyroid as a differential diagnosis when they come across any lytic lesion of the skuIl. Also if there is no thyroid enlargement and biochemical thyroid profile is normal in such cases, they should advise computerized tomography (CT), magnetic resonance imaging (MRI) and FNAC, histopathology of the lesion for early, correct diagnosis to exclude metastatic thyroid malignancies for better treatment of the patient.

\section{References}

1. Cotran RS, Kumar V, Collin T. eds. Robbins Pathologic Basis of Disease. $6^{\text {th }}$ edn. Philadelphia, WB Saunders Company 1999; 1144-45.

2. Wong GK, Boet R, Poon WS. Ng HK. Lytic skull metastasis secondary to thyroid carcinoma in an adolescent. Hong Kong Med J 2002; 8(2): 149-5 I.

3. Kim SH, Kosnik. E, Madden C, Morran S, Rusin J, Gordon T, Boue D. Lytic skull metastasis from a follicular carcinoma in a child. Pediatr Neurosurg 1998; 28(2): 84-8

4. Moudouni SM, En-Nia I, Rioux-Leclerq N, Manunta A, Guille F, L obel B. Follicular carcinoma of the thyroid metastasis to the kidney nine years after resection of the primary tumor. Ann Urol (Paris) 2002; 36(1): 36-7.

5. Caron P, Moreau-Cabarrot A, Gorguet B, Bazex J. Cutaneous metastasis from follicular carcinoma of the thyroid gland.Thyroid.1993 Fall; 3(3): 235-7.

6. Agarwal A, Mishra SK, Jain M. Follicular thyroid carcinoma with metastasis to the mandible. J Indian Med Assoc. 1998; 96(11): 354-5.

7. Rodroguez Carballeira M. Coll Roldua I, del Pozo Pico C, Soler Rich R, Garcia Pascual L, Balsells Coca M. Follicular cancer of the thyroid: a typical presentation. An Med lnterna 1995; 12(6): 291-3. 